\title{
Transpyloric feeding in 49 infants undergoing intensive care
}

\author{
ELIZABETH DRYBURGH
}

St James's University Hospital, Leeds

SUMMARY The use of transpyloric feeding in 46 very ill newborn infants requiring assisted ventilation was evaluated. It was found to be a simple and well-tolerated technique. A possible complication of significance was necrotising enterocolitis in 4 infants. Transpyloric tube feeding in 3 infants with treated upper small-bowel atresia is also described.

It is generally accepted that low birthweight infants, and those who are ill, benefit from early feeding and the provision of adequate calories in the early weeks of life. ${ }^{1-2}$ Achieving adequate caloric intake in seriously ill neonates, without compromising their respiratory status, is difficult. Nasogastric tube milk feeding in infants with respiratory distress may precipitate regurgitation, aspiration, and apnoea, and it may exacerbate existing respiratory symptoms. $^{3-4}$

Many of the problems associated with nasogastric feeding in infants with respiratory distress may be overcome by delivering the milk feed beyond the pylorus into the duodenum or proximal jejunum. Alternatively total parental nutrition can be used. Although total parenteral nutrition of infants undergoing intensive care is successful in many large neonatal intensive care units, the technique is complicated and is certainly not without serious complications. ${ }^{5}$ Transpyloric feeding is simpler and requires less biochemical monitoring and so can be used in smaller units with limited staff and laboratory resources.

\section{Patients and methods}

The infants studied were nursed in the infant intensive care area, Leeds General Infirmary (October 1977-March 1979) and in the special care baby unit, St James's Hospital, Leeds (MarchJune 1979). Transpyloric feeding was used in 46 infants receiving ventilatory assistance (intermittent positive pressure ventilation (IPPV) or continuous positive airways pressure for severe respiratory illness). All the infants had a nasotracheal tube in situ when the transpyloric tube was passed.

In 3 infants a transanastomotic feeding tube was passed during surgery for upper small-bowel atresia.

The range of gestational age of the 49 infants was 25-42 (mean 31.5) weeks. Birthweights ranged from 0.65 to 3.9 (mean 1.69 ) $\mathrm{kg}$. Further details of these infants are presented in Tables 1 and 2.

The commercially available silicone tube weighted with a stainless steel tip (Fr. gauge 5) was used (Vygon Ltd). The distance between the glabella and the outstretched heel was measured, and the length

Table 2 Infants fed by transanastomotic feeding tube after surgery for upper small-bowel atresia

\begin{tabular}{lllll}
\hline Case & Sex & Birthweight $(\mathrm{kg})$ & Gestation (weeks) & Site of atresia \\
\hline 1 & M & 3.67 & 40 & Duodenum \\
2 & F & 2.54 & 36 & Duodenum \\
3 & M & 3.01 & 42 & Jejunum \\
\hline
\end{tabular}

Table 146 infants requiring ventilatory assistance, fed via the transpyloric route

\begin{tabular}{|c|c|c|c|c|c|c|c|}
\hline \multicolumn{2}{|c|}{ Birthweight $(g)$} & \multirow[t]{2}{*}{$\%$} & \multirow{2}{*}{$\begin{array}{l}\text { Respiratory } \\
\text { distress }\end{array}$} & \multirow[t]{2}{*}{ Pneumonia } & \multirow{2}{*}{$\begin{array}{l}\text { Recurrent } \\
\text { apnoea }\end{array}$} & \multicolumn{2}{|c|}{ Survivorst } \\
\hline & & & & & & No & $(\%)$ \\
\hline $\begin{array}{l}<1000 \\
1001-1500 \\
1501-2000 \\
2001-2500 \\
>2500 \\
\text { Total }\end{array}$ & $\begin{array}{l}(n=8) \\
(n=20) \\
(n=5) \\
(n=9) \\
(n=4) \\
(n=46)\end{array}$ & $\begin{array}{r}17 \\
43 \\
13 \\
19 \\
8 \\
100\end{array}$ & $\begin{array}{r}6 \\
12 \\
4 \\
7 \\
0 \\
29\end{array}$ & $\begin{array}{l}1 \\
1 \\
0 \\
2 \\
4 \\
8\end{array}$ & $\begin{array}{c}2^{*} \\
10^{*} \\
2^{*} \\
0 \\
0 \\
14\end{array}$ & $\begin{array}{r}2 \\
12 \\
5 \\
8 \\
4 \\
31\end{array}$ & $\begin{array}{l}(25) \\
(60) \\
(100) \\
(89) \\
(100) \\
(63)\end{array}$ \\
\hline
\end{tabular}

*Few infants initially ventilated for respiratory distress subsequently required ventilation for recurrent apnoea.

†Some infants were transferred for ventilation but died before transpyloric feeding could be established. 
from the tip of the tube was marked using a small strip of green sticky tape. The tube was passed through a nostril and advanced until acid gastric juice could be aspirated, or if that proved impossible, until resistance was felt. The infant was then placed semi-prone on the right side and the tube was advanced at about $2-3 \mathrm{~cm}$ an hour until the marker reached the nostril. An attempt was then made to aspirate the tube. If bile-stained fluid was obtained feeding was started. On many occasions no fluid could be aspirated because the lumen of the soft Silastic tube had collapsed on suction. In these cases, $x$-ray confirmation of the position of the tube was obtained. The ideal position for the tip of the tube was thought to be in the 3rd or 4th part of the duodenum. ${ }^{6}$ The infants were nursed prone or on the right side when the tube was in situ.

Before feeding was started an orogastric tube (Fr. gauge 5) was passed for aspiration of the stomach. Expressed breast milk or a humanised cows' milk formula was continuously infused initially at $2 \mathrm{ml}$ an hour increasing gradually, if tolerated, to a total of $180-200 \mathrm{ml} / \mathrm{kg}$ per day. The orogastric tube was aspirated every 3-4 hours to ensure that the stomach was free of milk. Between aspirations the end of the tube was left open.

Care was taken to maintain the infant's $\mathrm{Po}_{2}$ during the passage of the tube. Continuous $\mathrm{Po}_{2}$ monitoring, either via an umbilical arterial $\mathbf{P o}_{2}$ electrode or via a transcutaneous $\mathrm{Po}_{2}$ electrode, was carried out in most cases.

\section{Results}

In only one infant was the technique unsuccessful despite several attempts. She was fed by the intravenous route. In another infant the respiratory distress improved so rapidly that attempted transpyloric intubation was stopped at 24 hours.

The technique was successful on 81 occasions in 44 infants. The tube was passed on more than one occasion in 21 infants because of accidental displacement or blockage of the tube, or recurrence of symptoms. The time taken to place the tube successfully is shown in Table 3. The tube was passed in less than 12 hours in $83 \%$ of attempts. As with most practical procedures, results improve

Table 3 Time taken to pass transpyloric tube

\begin{tabular}{lll}
\hline \multicolumn{2}{l}{ Time (hours) } & $\%$ \\
\hline$<6$ & $(\mathrm{n}=53)$ & 64 \\
$6-11$ & $(\mathrm{n}=16)$ & 20 \\
$12-24$ & $(\mathrm{n}=8)$ & 10 \\
$>24$ & $(\mathrm{n}=4)$ & 5 \\
Not passed $(\mathrm{n}=2)$ & 2 \\
\hline
\end{tabular}

with practice and $97 \%$ of the last 40 attempts were successful in less than 6 hours.

It was necessary to obtain an upper abdominal $x$-ray to confirm the position of the tube in most infants because the Silastic tube had collapsed on attempted aspiration. If bile-stained aspirate was obtained an $x$-ray was not considered necessary. Every effort was made to achieve confirmation of the site of the tube when a chest $x$-ray was being taken to assess progress of the respiratory illness. The nasoduodenal tube was in position for between 1 and 56 (mean 9.5) days. It was usually placed during the first or second day of life, but in 6 infants it was sited later because of delayed onset of the respiratory illness.

Minor weight loss during the first week of life was usual, although $23 \%$ of the infants did not lose any weight. The mean weight loss was 120 (range 0-250) g. All infants gained weight after they were 7-days old. The mean weight gain was $27.5 \mathrm{~g}$ a day: half of the infants had regained their birthweight by the 10th day, $92 \%$ by the 14th day.

Complications of the method are summarised in Table 4. The most common complication was accidental displacement of the tube. On several occasions it was inadvertently pulled out by staff, generally during a crisis-such as reintubation for blocked endotracheal tube. More often however, the infant pulled out the tube. In an attempt to prevent this the infants wore mittens.

Diarrhoea was also a common but usually a transient complication. In all cases but one the diarrhoea responded to a temporary reduction in volume of feed or to the substitution of a lowlactose milk. Vomiting, despite the fact that the tube was confirmed to be beyond the pylorus, occurred twice. This also responded to reduction of volume of feed. The tube blocked on two occasions and was replaced.

The only serious complication was necrotising enterocolitis (NEC) which occurred in 4 infants. The diagnosis was made clinically in all 4 because of abdominal distension, bile-stained aspirate, and rectal bleeding; it was confirmed in 2 by $x$-ray and necropsy. In a further 2 infants transpyloric feeding was temporarily stopped because of blood in the stools. The rectal bleeding was associated in both instances with a coagulation disorder.

Table 4 Complications

\begin{tabular}{lrr}
\hline Complication & & $\%$ \\
\hline Accidental displacement of tube & $(n=21)$ & 43 \\
Diarrhoea & $(n=9)$ & 18 \\
Vomiting & $(n=2)$ & 4 \\
Tube blocked & $(n=2)$ & 4 \\
Necrotising enterocolitis & $(n=4)$ & 8 \\
\hline
\end{tabular}


Table 5 Details of the 4 infants with necrotising enterocolitis

\begin{tabular}{|c|c|c|c|c|c|c|c|}
\hline \multirow[t]{2}{*}{ Case } & \multirow[t]{2}{*}{ Sex } & \multirow{2}{*}{$\begin{array}{l}\text { Birthweight } \\
(\text { kg) }\end{array}$} & \multirow{2}{*}{$\begin{array}{l}\text { Gestation } \\
\text { (weeks) }\end{array}$} & \multicolumn{2}{|c|}{ Apgar score } & \multirow{2}{*}{$\begin{array}{l}\text { Umbilical } \\
\text { catheter }\end{array}$} & \multirow[t]{2}{*}{ Outcome } \\
\hline & & & & $1 \mathrm{~min}$ & $5 \min$ & & \\
\hline $\begin{array}{l}4 \\
5 \\
6 \\
7\end{array}$ & $\begin{array}{l}\mathbf{M} \\
\mathbf{F} \\
\mathbf{M} \\
\mathbf{M}\end{array}$ & $\begin{array}{l}1 \cdot 6 \\
1 \cdot 04 \\
1 \cdot 23 \\
1 \cdot 0\end{array}$ & $\begin{array}{l}32 \\
30 \\
32 \\
28\end{array}$ & $\begin{array}{l}1 \\
3 \\
1 \\
2\end{array}$ & $\begin{array}{l}4 \\
7 \\
4 \\
6\end{array}$ & $\begin{array}{l}\text { Present } \\
\text { Present } \\
\text { Present } \\
\text { Present }\end{array}$ & $\begin{array}{l}\text { Survived } \\
\text { Died** } \\
\text { Died } \\
\text { Died }\end{array}$ \\
\hline
\end{tabular}

* Case 5 had completely recovered from NEC before her death.

\section{Discussion}

The maintenance of adequate nutrition in neonates undergoing intensive care for severe respiratory distress or recurrent apnoea presents many problems. Total parenteral nutrition has been used successfully under these circumstances ${ }^{7-8}$ but the technique is complicated and expensive, and close biochemical monitoring is essential. Transpyloric milk feeding however, is a fairly simple and cheap technique and requires less monitoring.

In this study transpyloric feeding was well tolerated by even the sickest infants requiring ventilation. There were no episodes of aspiration pneumonia; there was no deterioration either clinically or in blood-gas measurements when feeding began. The method in this group was probably more successful than in a comparable group of infants requiring respiratory assistance at the Hammersmith Hospital ${ }^{9}$ for three main reasons: (1) assisted ventilation was via an endotracheal tube and not via a face mask; (2) the transpyloric tube was passed via the nose and not the mouth; (3) apnoea was not an indication for stopping transpyloric feeding (although it must be emphasised that $\mathbf{4 3}$ of the $\mathbf{4 4}$ infants were on IPPV at least at the outset).

Silastic feeding tubes were used because of the association of polyvinyl chloride feeding tubes with intestinal perforation and NEC. ${ }^{10-13}$ Recently, however, perforation with a Silastic tube was described. ${ }^{14}$

Most of the tubes were passed by one person (E D). The time taken to position the tube was $<6$ hours in $64 \%$ of attempts. All except 2 were passed in less than 48 hours. This compares most favourably with the figures of Cheek and Staub, ${ }^{15}$ Wells and Zachman, ${ }^{16}$ and Beddis and McKenzie. ${ }^{9}$ Towards the end of the study period the tubes were being passed by a few senior nursing staff, with close attention to technique. Their success rate was comparable with mine.

The major practical problem encountered was maintaining the tube in situ. Despite firmly fixing at the nose, and putting mittens on the infant, the tube was often displaced. The feed was immediately stopped until it had been resited.
The mean weight gain of $27.5 \mathrm{~g}$ a day and the return to birthweight by the 14th day in $92 \%$ of infants is highly satisfactory when one considers how ill they all were. Clinical oedema was present in only 2 infants.

The use of transanastomotic feeding tubes in 3 infants with upper small-bowel atresia allowed earlier introduction of enteral feeds. Total parenteral nutrition was avoided in 1 infant and shortened in the other 2. No complication occurred in this small group.

The part played by transpyloric feeding in the aetiology of NEC is difficult to determine. Many predisposing factors to NEC (for example, low birthweight, perinatal asphyxia, and umbilical catheters) have been described. ${ }^{17}$ Some or all of these factors were present in each of the cases of NEC (Table 5).

It is interesting that during the study period NEC occurred in two 'outbreaks'. Of a total of 9 infants affected, 4 were fed via the transpyloric route and 5 via the nasogastric or oral route. Since the study ended a further 12 infants have been fed transpylorically, with no further cases of NEC.

Yu et $a l .^{8}$ described 4 cases of NEC in critically ill, low birthweight infants fed via the nasogastric route; none of their infants who was totally parenterally nourished suffered from the condition. It seems likely that milk feeding critically ill, low-birthweight infants predisposes to NEC but whether the transpyloric or intragastric route influences the aetiology is debatable.

The study shows that transpyloric feeding in very ill newborn infants is simple, well tolerated, and is relatively safe.

I thank Professor R W Smithells, Dr M G Buchanan, Dr W I Forsythe, Dr J M Littlewood, and Mr J Beck for permission to study infants under their care.

\section{References}

1 Smallpeice V, Davies P A. Immediate feeding of premature infants with undiluted breast milk. Lancet 1964 ; ii: 1349-52.

2 Winick M. Malnutrition and brain development. J Pediatr 1969; 74: 667-79. 
3 Daily W J R, Klaus M, Meyer H B P. Apnoea in premature infants: monitoring incidence, heart rate changes, and effect of environmental temperature. Pediatrics 1969 ; 43: 510-8.

4 Yu V Y H. Cardiorespiratory response to feeding in newborn infants. Arch Dis Child 1976; 51 : 305-9.

5 Cockburn F. Parenteral nutrition in the newborn. Br $J$ Hosp Med 1977; 18: 191-201.

6 Hyde J. Transpyloric feeding in the newborn. Br J Hosp Med 1978; 19: 618-22.

7 Driscoll J M, Jr, Heird W C, Schullinger J N, Gongaware $\mathbf{R} \mathbf{D}$, Winters $\mathbf{R} \mathbf{W}$. Total intravenous alimentation in low birthweight infants: a preliminary report. $J$ Pediatr $1972 ; 81$ : 145-53.

8 Yu V Y H, James B, Hendry P, MacMahon R A. Total parenteral nutrition in very low birthweight infants-a controlled trial. Arch Dis Child 1979; 54: 653-61.

9 Beddis I, McKenzie S. Transpyloric feeding in the very low birthweight (1500g and below) infant. One year's experience in an intensive care neonatal unit. Arch Dis Child 1979; 54: 213-7.

10 Boros S J, Reynolds J W. Duodenal perforation: a complication of neonatal nasojejunal feeding. $J$ Pediatr 1974; 85: 107-8.

11 Chen J W, Wong $\mathbf{P}$ W K. Intestinal complications of nasojejunal feeding in low birthweight infants. $J$ Pediatr 1974; 85: 109-10.

12 Loo S W H, Gross I, Worshaw J B. An improved method of nasojejunal feeding in low birthweight infants. $J$ Pediatr 1974; 85: 104-6.

13 Sun S C, Samuels S, Lee I, Marquis J R. Duodenal perforation: a rare complication of neonatal nasojejunal tube feeding. Pediatrics $1975 ; 55$ : 371-5.

14 Pérez-Rodrigues J, Quero J, Frias E G, Omenaca F. Duodenal perforation in a neonate by a tube of silicone rubber during transpyloric feeding. J Pediatr 1978; 92: 113-4.

15 Cheek J A, Jr, Staub G F. Nasojejunal alimentation for premature and full term newborn infants. $J$ Pediatr 1973; 82: 955-62.

16 Wells D H, Zachman R D. Nasojejunal feeding in low birthweight infants. J Pediatr 1975; 87: 276-9.

17 Anonymous. Necrotising enterocolitis. $\mathrm{Br} \mathrm{Med} J$ 1978; i: 132.

Correspondence to Dr E Dryburgh, Department of Paediatrics, Peterborough District Hospital, Thorpe Road, Peterborough PE3 6DA.

Received 6 November 1979 